\title{
CONEXÕES ENTRE PENSAMENTO SISTÊMICO, CONSTELAÇÕES SISTÊMICAS E DIREITO SISTÊMICO
}

Grazielly Alessandra Baggenstoss ${ }^{1}$

Resumo: As constelações sistêmicas são práticas restaurativas que pretendem a composição de conflitos e vem sendo utilizadas pelo Poder Judiciário Brasileiro. Diante disso, questiona-se qual a relação desse método com o pensamento sistêmico e, também, com o denominado Direito Sistêmico. A partir do modelo epistêmico do pensamento sistêmico, pelo método dedutivo, pretende-se explanar sobre as diferenças epistemológicas entre os modelos científicos mencionados. Seguidamente, apresenta-se uma panorâmica conceitual e procedimental das constelações sistêmicas e, finalmente, expõe-se o esforço de refletir sobre a representação do direito sistêmico.

Palavras-chave: Pensamento sistêmico; Contelações sistêmicas; Direito sistêmico.

\section{CONNECTIONS BETWEEN SISTEMIC THINKING, SYSTEMIC CONSTELLATION AND SYSTEMIC LAW}

\begin{abstract}
Systemic constellations are restorative practices that seek the composition of conflicts and are being used by the Brazilian Judiciary. In view of this, it is questioned about the relation of this method to systemic thinking and also to the systemic law. From the epistemic model of systemic thinking, by the deductive method, this work explain the epistemological differences between the mentioned scientific models. Next, a conceptual and procedural overview of the systemic constellations is presented and, finally, the effort to reflect on the representation of the systemic law.
\end{abstract}

Keywords: Sistemic Thinking; Constellations; Systemic Law.

\section{CONSIDERAÇÕES INICIAIS}

Contemporaneamente, duas concepções metodológicas destacam-se nas percepções e abordagens fenomênicas: o modelo cartesiano e o modelo sistêmico. O pensamento cartesiano, ou mecanicista, prioriza o processo analítico, em que se pretende a compreensão dos objetos

\footnotetext{
${ }^{1}$ Doutora em Direito, Política e Sociedade (UFSC), Mestra em Direito, Estado e Sociedade (UFSC), Doutoranda em Psicologia, com ênfase em Desenvolvimento Humano. Professora da Universidade Federal de Santa Catarina, Classe Adjunto, atuante no Curso de Graduação em Direito, no Programa de Pós-Graduação em Direito (PPGD) e no Programa de Pós-Graduação Profissional em Direito (PPGPD) nas disciplinas de Direito e Feminismos, Hermenêutica Jurídica, Prática Jurídica e Metodologias do Ensino Jurídico e da Pesquisa. Pesquisadora Líder do Grupo de Pesquisa/CNPq "Lilith: Núcleo de Pesquisas em Direito e Feminismos" da Universidade Federal de Santa Catarina. Pesquisa sobre sistemas sociais, epistemologias e análise discursiva jurídica.
} 
com clara delimitação de suas fronteiras e com a sua decomposição, visando à simplicidade e ao reducionismo. Já o pensamento sistêmico reveste-se de um método preocupado com a integração e o dinamismo do todo, a ser verificado nas relações circulares entre partes e partes, e entre estas e o todo, e, ainda, entre o todo e outras totalizações.

Até o momento presente, tem-se a estruturação primordial dos modos de conhecimento com base no paradigma cartesiano. Contudo, diante da sua falibilidade nas hipóteses de se observar fenômenos complexos, emerge a concepção sistêmica, que prima por um exame mais multidisciplinar de determinado objeto de estudo.

Por conseguinte, nota-se a utilização crescente de termos correlatos, como subjetividade, posição, locais, sistemas, estrutura sistêmica. E, chegando na esfera jurídica, uma técnica que vem sendo bastante difundida no meio jurídico é a de constelações sistêmicas ${ }^{2}$, com a proposta de resgatar os vínculos entre as pessoas pertencentes a um determinado sistema com a utilização técnicas de terapia no tratamento de divergências e conflitos. Tal forma de pacificar conflitos, afiançada pelo Conselho Nacional de Justiça, apresenta-se, por ora, em conformidade com a Resolução CNJ no. 125/2010, que incentiva o objetivo de tratar situações conflituosas de modo restaurativo.

Diante disso e da suposta ligação entre os termos pensamento sistêmico e constelação sistêmica, lança-se, como questionamento, qual a relação existente entre pensamento sistêmico, constelações sistêmicas e direito sistêmico.

A partir do modelo epistêmico do pensamento sistêmico, especialmente em referência às teorias de Bertalanffy e João Bosco da Mota Alves, pelo método dedutivo, pretende-se explanar sobre as diferenças epistemológicas entre os modelos científicos mencionados, bem como destacar algumas construções teóricas e expoentes notados do pensamento sistêmico, com relevo à análise do Direito por tal molde. Seguidamente, apresenta-se uma panorâmica conceitual e procedimental das constelações sistêmicas e, finalmente, expõe-se o esforço de refletir sobre a representação do direito sistêmico.

\footnotetext{
${ }^{2}$ Cf. Conselho Nacional de Justiça. "Constelação Familiar" ajuda a humanizar práticas de conciliação no Judiciário. Disponível em <http://www.cnj.jus.br/noticias/cnj/83766-constelacao-familiar-ajuda-humanizarpraticas-de-conciliacao-no-judiciario-2> Acesso em $28 \quad$ mar $\quad 2018$; e CONJUR. Doze tribunais adotam técnica alemã de conciliação em conflitos Disponível em <https://www.conjur.com.br/2016-nov-01/doze-tribunais-adotam-tecnica-alema-conciliacaoconflitos>. Acesso em 28 mar 2018.
} 


\section{EPISTEMOLOGIA DO PENSAMENTO CARTESIANO E DO PENSAMENTO SISTÊMICO}

Desde o século XVII, a forma com que analisamos os fenômenos da realidade é guiada pelo pensamento de que, quanto mais específica for amplitude de observação de um evento, mais facilmente poderemos compreendê-la e solucionar eventuais problemas ${ }^{3}$.

O nome desse método de análise da realidade é o Cartesianismo, ou visão ou pensamento cartesiano. Renè Descartes, expoente do método, propõe sua leitura a partir da análise e da síntese: aquela, caracterizada pela divisão do fenômeno (seja natural ou mental), que será observado de acordo com as partes necessárias para chegar a constituintes passíveis de entendimento e explicação racional; e esta, caracterizada pelo conjunto das partes dos elementos constituintes, o qual forma o todo (LAKATOS; MARCONI, 1991).

Para tanto, o método cartesiano de observação da realidade pressupõe quatro regras:

a) a regra da evidência: a qual estabelece que não se exclui qualquer elemento a não ser que haja evidências que justifiquem a exclusão;

b) a regra da análise: que determina a divisão do objeto no maior número de partes possível para estudo;

c) a regra da síntese: que impõe a reestruturação do conjunto separando as verdades independentes das verdades derivadas, ordenadas conforme as relações existentes entre elas; e

d) a regra da enumeração: que sugere a seleção dos elementos necessários e suficientes para elaborar uma verdade sobre o objeto em estudo, sem omissões nem excessos (DESCARTES, 1996).

Percebe-se, pois, que o pensamento cartesiano orienta para que a explanação do mundo dê-se a partir de uma observação do mundo de modo reduzida, a fim de que sejam analisados os seus componentes básicos de uma determinada realidade e com a análise fragmentada desses. Assim, tal método prima pela simplicidade, pois enquadra os fenômenos em relações causais lineares, e pela estabilidade, pautando-se pela previsibilidade, controlabilidade e objetividade (CAPRA, 2012).

\footnotetext{
${ }^{3}$ A Teoria dos Sistemas e os paradigmas científicos foram abordados em BAGGENSTOSS, Grazielly A. Teoria dos sistemas humanizada: a modelagem garantista das funções jurisdicional e legislativa. Rio de Janeiro: Lumen Juris, 2015.
} 
A visão cartesiana promoveu o impulso, desse modo, de uma ciência objetiva e um tanto quanto reducionista, a qual se enraizou tão profundamente na cultura ocidental que passou a ser confundido com o que se entende como método científico.

Além disso, a cultura ocidental, visando à objetividade, também se tornou progressivamente fragmentada e culminou no desenvolvimento de uma tecnologia, instituições e estilos de vida doentios, tendo em vista o desprezo que prega a definições e explicações que fogem de seu método (CAPRA, 2012).

Para Bertalanffy (1969, p. 30), por conseguinte,

[...] o físico, o biólogo, o psicólogo e o cientista sociais [passaram a estar], por assim dizer, encapsulados em seus próprios universos privados, e é difícil o diálogo científico entre os mesmos. Isto, entretanto, se opõe a outro aspecto significativo. Observando a evolução da ciência moderna, encontramos um fenômeno surpreendente. De forma independente, problemas e concepções similares evoluíram em campos claramente distintos.

Aqui não se perde a importância do pensamento cartesiano: é justificada, portanto, a necessidade de especialização que direcionou a atomização da ciência. No entanto, “efeitos de segunda orem se fizeram inevitáveis, como o que se poderia chamar de ‘invenção da roda’ feita várias vezes, de forma independente, em disciplinas onde quer que fosse necessário, ou seja, repetida em universos conceituais aparentemente distintos (ALVES, 2012, p. 156).

A título de ilustração, veja-se o formato da medicina, dos currículos escolares, da formatação das entidades jurídicas, especialmente as brasileiras. Vê-se a campos de conhecimento pertinentemente fragmentados, divididos a fim de se alcançar a sua especialização em uma determinada área. Contudo, não se verifica, comumente, na análise da agregação de tais elementos, a fim de que este conjunto de fatores determinados sejam observados de forma integral. Mais que isso: a própria consideração da figura humana, em seus mais diversos âmbitos de atuação, não é realizada de forma integral, percebendo-se sua complexidade, mas sim de forma parcial, com destaque, tão somente, a aptidões que seja úteis ao espaço fragmentado, como a força de trabalho, ou o sucesso na competição.

Igualmente no âmbito empresarial, verifica-se a evolução dos meios de produção e, também, dos critérios de gestão. Nos termos de Alves (2012, p. 159): 
A explosão populacional e a limitação de recursos não renováveis do planeta Terra, bem como as condições ambientais crescentemente adversas, impõem às empresas modernas tal responsabilidade social, que confronta a motivação única no lucro e na escala.

É assim que a realidade passou a se mostrar em um tal grau de complexidade que a propositura de soluções reducionistas, pautadas pela visão cartesiana, mostrou-se insuficiente. Assim, considerando que a sociedade contemporânea apresenta um entrelaçamento não linear, não processual e não metódico dos fenômenos, surgem novos pressupostos epistemológicos: a complexidade, pelas contradições existentes, a instabilidade, em razão da desordem verificada, e a intersubjetividade, diante das incertezas.

A reflexão do contexto atual ocidental pelo método cartesiano tão somente acarreta a distorção da percepção em situações complexas; isso porque, ao se separar um todo em suas partes constituintes, corre-se o risco de se perderem as relações que permeiam e interligam o sistema. Por isso que se afirma que a visão mecanicista tornou-se inadequada a tentativa de promover o desenvolvimento do conhecimento científico como um processo linear de evolução (CAPRA, 2012).

Os fenômenos da sociedade contemporânea interligam-se em uma teia em que início, fim, causa e consequência estão vinculados. Devem ser enfrentados, pois, os desafios explicativos que antes eram relegados pelo método cartesiano, como a instabilidade, a incerteza e a indefinição (COLOM, 2004). No ambiente complexo, portanto, inexiste um sentido a ser seguido, mas sim um contexto em que a certeza, dependendo do ângulo de onde se observa, é o caos (TRINDADE, 2008), o qual deve fator considerado nas análises dos sistemas sociais, bem como nos processos científicos das mais diversas áreas do pensamento.

Ora, percebeu-se que as soluções para os problemas não estavam somente em partes e processos considerados de forma isolada; seria necessário ir adiante e também procurar a resolução na organização e na unificação das partes/processos, que seria produto da interação dinâmica das partes, tendo em vista que esse dinamismo promove diferentes comportamentos das partes quando estudadas isoladamente ou no contexto do todo (ALVES, 2012).

Diante da deficiência da metodologia analítica para o enfrentamento da realidade contemporânea, tem-se a necessidade de construção e aplicação de novos paradigmas fundantes 
do pensamento científico que relacione as expectativas do ambiente complexo (TRINDADE, 2008).

Essa imprescindibilidade originou a noção de conhecimento sistêmico, o qual se desenvolveu simultaneamente com diversas disciplinas na primeira metade do século passado, tendo como pioneiros os biólogos, que examinavam a concepção dos organismos vivos como totalidades integrantes, e os estudiosos da cibernética. Posteriormente, acresceram-se estudos relacionados à psicologia de Gestalt, à ciência da ecologia, à física quântica (CAPRA, 1999), assim como à psicologia sistêmico-familiar, à administração, à gestão de conhecimento, dentre outros.

A estruturação de uma forma de pensar mais integrada surge, portanto, de um movimento de reconhecimento da importância dos desafios explicativos da sociedade complexa, a qual passou a ser apresentada por um modelo de reestruturação do conhecimento atual diversa da análise, em que se reduz a complexidade e amplia-se a sua gama de incidência. A essa forma de observação da realidade, dá-se o nome de pensamento sistêmico.

Pelo pensamento ou método sistêmico, examina-se o meio complexo de uma postura científica igualmente complexa, em que a ordem de as partes não mais determina o todo, mas é o todo que determina o sentido contextual das partes e interfere nas suas relações (TRINDADE, 2008).

Nesse compasso, a funcionalismo dos sistemas passa a ter destaque em detrimento da percepção analítica e da especialização de certezas. Na estrutura dos sistemas, o questionamento sobre as razões fundantes e motivadoras fica em segunda ordem: a atenção dirige-se à sua função e às interações que tal sistema realiza com os demais sistemas, assim como as relações internas de seus elementos integrantes (TRINDADE, 2008). Por isso, o método sistêmico não determina qual o paradigma último a fundamentar de forma inquestionável - eis que inexistente -, mas propicia um panorama holístico e funcional do ambiente. O pensamento sistêmico inova no modo de se perceber os fenômenos do mundo e tem a pretensão de solucionar problemáticas complexas que se mostraram irresolúveis para o método cartesiano. Assim, verifica-se uma complementaridade em tais pensamentos, mas também divergências. O pensamento sistêmico enfatiza mais o todo do que a parte isolada e atomizada e considerar, em um sistema integrado, todos os elementos influenciadores em determinado fenômeno, a relação entre eles e a circularidade relacional com o todo (SENGE, 2013).

Nessa linha de pensamento, a verificação de um fenômeno deve reconhecer a inclusão de variáveis relevantes, mesmo que isso represente uma contradição, ou o aumento da 


\section{CONEXÕES ENTRE PENSAMENTO SISTÊMICO, CONSTELAÇÕES SISTÊMICAS E DIREITO SISTÊMICO}

complexidade ou a inclusão da subjetividade - que são peculiaridades típicas observadas nesse método. Assim, em sentido oposto à concepção cartesiana de conhecimento fragmentado dos objetos que compõem o todo, o método sistêmico prioriza as relações entre os elementos relevantes ao fenômeno (SENGE, 2013).

Nesse linha de raciocínio, no pensamento sistêmico, a hierarquia é substituída pelo dinamismo em rede, bem como se abandona a causalidade linear, típica do pensamento cartesiano, e adota-se a circularidade. Naquele, a compreensão de um determinado fenômeno refere-se ao levantamento dos dados e ao reconhecimento de padrões, em que se verificam as explicações causais do que é estudado (assim, as relações tautológicas ou de exceção remanesceram excluídas ou em segundo plano). Esta, inspirada na cibernética e na engenharia de controle, reconhece a imprescindibilidade do exame das relações circulares e defende que, sem o entendimento de tais relações circulares, a compreensão do todo fica limitada. Assim, propõe a busca pelo panorama integral da ocorrência de determinado fenômeno por meio dos fluxos circulares, no lugar de apenas serem consideradas relações lineares de causa e efeito. Além disso, nota-se a consideração da estrutura de determinado fenômeno evidenciada pela primazia de seus processos, que é o que estabelece padrões de organização e permite a materialização da estrutura. É aqui que se destacam a teoria da autopoiese, originalmente de Maturana e Varela, e a teoria das estruturas dissipativas de Prigogine. Ainda, no intuito de pretender alcançar uma teoria integradora entre estruturalismo e funcionalismo, destacam-se autores como Niklas Luhmann, e Jürgen Habermas.

Na evolução do pensamento sistêmico, demonstrada por teorias biológicas, ou de engenharia do controle (Talcott Parsons), pela teoria cibernética (Prigogine, Habermas), por teorias sociológicas e psicológicas.

A proposta do pensamento sistêmico, então, é vislumbrar os princípios básicos de organização e a adoção de equilíbrio entre tendências opostas, como reducionismo e holismo, análise e síntese - o que o caracteriza como um método que incorpora contradições e complexidade. Esse modelo, por consequência, comporta, na análise de determinado fenômeno, a consideração de todos os fatores relevantes que influem na verificação da ocorrência do objeto observado. Além disso, o pensamento sistêmico possibilita a passagem do comportamento de controle para a cooperação, a influenciação e a ação não violenta ${ }^{4}$. Para tanto, considera-se a

\footnotetext{
${ }^{4}$ Cf. NAGLER, Michael. The search for a nonviolent future. California: Berkeley Hills Books, 2001; MATURANA, Humberto; VARELA, Francisco. Árvore do conhecimento: as bases biológicas da compreensão humana. São Paulo: Palas Athena, 2010.
} 
hipótese de estudos ecológicos de que são insustentáveis os sistemas humanos hierárquicos movidos pelo controle unilateral e que a postura cooperativa é a que permite a evolução dos sistemas e da humanidade ${ }^{5}$.

\subsection{Sistemas: definição, pensamento sistêmico, postura do observador}

Por Andrade (2014, p. 7), o pensamento sistêmico é uma forma de raciocinar que se orienta por características sistêmicas, incentivando a uma capacidade de notar, modelar e avaliar as consequências das ações de maneira expandida, no critérios temporais e espaciais.

Assim:

[...] resulta em uma maneira de cogitar e modelar a complexidade do mundo que tem por base processos característicos do paradigma sistêmico, que privilegia o todo, os relacionamentos, a visão de rede, a lógica de causa-e-efeito distantes (circularidade, atrasos), a consideração dos processos dinâmicos, o uso da metáfora do organismo vivo, a estruturação de conhecimento socialmente construído (epistêmico e contextual), a aceitação das descrições aproximadas e das medidas qualitativas [...], a abordagem intelectual contextualista, uma atitudes contemplativa e de perplexidade diante do caos e incerteza, resultando em ação por auto-organização que adota processo de aprendizagem transdisciplinar, experiencial, construtivista e generativo (ANDRADE, 2014, p. 7-8).

A partir disso, podem ser adotados três definições de pensamento sistêmico: (a) capacidade de perceber o todo de maneira expandida no tempo e no espaço; (b) processo mental baseado nas ideias sistêmicas de primazia dos relacionamentos, da circularidade, da rede, dos processos dinâmicos e do todo; (c) arte e disciplina de levar a mente a contemplar movimentos de religação circular produtores de redes representativas de todos (ANDRADE, 2014, p. 8).

\footnotetext{
5 “Logo, a atitude postulada por Bacon, de dominação e tortura da natureza com vistas ao seu domínio e controle, também pode ser encarada como uma atitude não sustentável na relação com a comunidade da vida. Essas percepções implicam a necessidade de uma mudança da atitude de dominação e controle da natureza, incluindo os seres humanos, para um comportamento cooperativo e de não-violência, tanto na ciência quanto na tecnologia, organização e sociedade” (ANDRADE, 2012, p. 168).
} 
Por conseguinte, o termo sistema pode ser definido "uma construção mental de uma organização contendo uma coleção de objetos inter-relacionados perfazendo um todo (uma unidade) com alguma funcionalidade que o identifica como tal” (ALVES, 2012, p. 96), destacando-se que é resultado da construção mental de seu observador, haja vista que "a observação permite ao ser humano ter uma visão de mundo individual e única” (ALVES, 2012, p. 96).

Essa consideração é extremamente relevante a fim de que seja trazido o observador de um sistema para a integração do contexto observado: é a projeção de análise do observador que destacará os elementos contidos em um sistema que serão relevantes; mais que isso: é a percepção do observador/pesquisador que formará a própria construção de um dado sistema. Nessa senda:

Um conjunto de aspectos, resultantes do processo de observação, é que forma a visão de mundo do observador [...]. a reflexão sobre esses aspectos pode levar o observador, por via da abstração, a isolar alguns que lhe pareçam relevantes. Se tais aspectos guardarem relações capazes de formar uma unidade funcional, a inferência é imediata: o observador acaba de construir mentalmente um sistema [...] Uma visão de mundo pode conter inúmeros sistemas. Todos, entretanto, são construções mentais que, eventualmente, tentam representar sistemas físicos. Diz-se eventualmente porque é possível construir mentalmente um sistema que ainda não existe fisicamente, podendo mesmo nem vir a existir (ALVES, 2012, p. 96; 97-98).

Em tal modo, tanto a empresa quanto o organismo vivo podem ser catalogados na rubrica de sistema, dependendo da percepção do observador/pesquisador ${ }^{6}$ - o qual deverá ter a intenção para tanto, o que significa que uma pessoa pode construir um sistema a partir de uma coleção de objetos satisfazendo uma destinação prévia (ALVES, 2012, p. 98).

\footnotetext{
${ }^{6}$ Detidamente, “[...]ambos - organismo e empresa - tem estrutura própria e fronteiras delimitadoras de seus respectivos ambientes. No entanto, a catalogação como sistemas só é possível porque há a figura do observador. E basta, pois seremos nós (eu, você e outro ser humano) a estuda-los; seremos nós a fazer ciência. Uma vez catalogado como sistema, organismo vivo, empresa, etc., podem ser estudados como tal” ) (ALVES, 2012, p. 159).
} 


\subsection{Perspectivas sistêmicas: autores e teorias}

Como já mencionado, o pensamento sistêmico molda-se em uma escola transdisciplinar, que congrega autores e suas teorias dos mais diversos campos de conhecimento.

Na Escola Sistêmica, então, tem-se - exemplificadamente -, os seguintes autores, construções teóricas, filosóficas e paradigmas: Engenharia de Controle, Eletrodinâmica, Funcionalismo sistêmico social (com Talcott Parcons), Teoria Geral dos Sistemas (por Bertalanffy), Física Quântica, Tradições filosóficas orientais, Gestalt e Linhas sistêmicas de psicologia, Dinâmica de sistemas pela biologia organísmica, Teoria da evolução de Darwin, Estruturas Dissipativas de Prigogine, Hipótese de Gaia, Holismo e Esoterismo, Teoria de Jürgen Habermas, Ecologia, Teoria do Caos, Matemática da Complexidade, Pensamento Complexo (com Edgar Morin), Organizações Sistêmicas Quânticas, em Rede, Teoria das Restrições, Aprendizagem Organizacional, Empresa Viva, Pensamento por Processos, Thinking Design, Teoria U, Teorias Orgânicas Sostemicas, Sistemas Sociais Autopoiéticos (como em Niklas Luhmann), Cibernética (ANDRADE, 2014).

Para além do método, o autor Bertalanffy (1969) promove a estruturação da Teoria Geral dos Sistemas, mencionando sobre as suas diretrizes podem ser aplicadas a qualquer sistema em geral, independentemente da natureza física, biológica ou sociológica. Dessa forma, pode ser aplicada na Física, que promove estudos sobre sistemas de diferentes níveis de generalidade, considerando que a Teoria da Relatividade é concretizada em sistemas macros, enquanto a Mecânica Quântica, em sistemas micros; ainda em contextos de construção de pontes ou máquinas; Mecânica ou Ótica; Termodinâmica, etc. (ALVES, 2012, p. 160-161).

Podem ser citados, ainda, no campo das ciências exatas, Alan Turing (fez um artigo sobre a teoria da morfogênese, em 1952, mais tarde desenvolvida por Rupert Sheldrake, médico que desenvolveu a referida teoria); no campo das ciências naturais, o já mencionado Bertalanffy, Barbara Ann Brennan (astrofísica da NASA, que estudou o campo energético humano); no campo das ciências humanas, teorias médico-psicanalistas, com Wilhelm Reich (professor de Barbara Brennan, médido e psicanalista); no campo das ciências humanas, teorias filosóficas de Frijot Capra, Maturana e Varela (inicialmente considerados no campo da biologia), Edgar Morin, Pedro Demo; teorias da psicologia, como Redes sociais significantes, Psicologia social, Psicologia sistêmica; no campo das ciências sociais, na Administração, como Peter Senge. 
No campo das ciências sociais aplicadas, também há autores que trabalham, especificamente o Direito, no viés sistêmico. Tem-se assim, por exemplo, Norberto Bobbio, ao teorizar sobre a coerência e a compatibilidade do sistemo jurídico; e os já mencionados Jürgen Habermas e Niklas Luhmann, especificados a seguir.

\subsection{Abordagem sistêmica do Direito em Jürgen Habermas e Niklas} Luhmann

No campo interdisciplinar contemplado pelo Direito, pode-se apontar dois autores importantes na concepção sistêmica da produção jurídica intraestatal e internacional, quais sejam Jürgen Habermas e Niklas Luhmann.

Jürgen Habermas estrutura seu pensamento sistêmico verificando quais são funções que devem ser exercidas pelos sistemas sociais, as quais justificam a formação dos mesmos, e também a análise da carência de tal cumprimento. Assim, vê-se a dimensão prescritiva, como referencial objetivo, e a dimensão descritiva, como referência fática.

Segundo Jürgen Habermas, as sociedades atuais podem ser definidas como um conjunto sistemático hipercomplexo, que apresenta constantes alterações em seus elementos sistêmicos e/ou nos valores-meta (“em que estão interligadas as definições culturais de vida social e os imperativos da sobrevivência que podem ser reconstruídos em teorias de sistema”7), com o objetivo de que sejam mantidos em um nível de controle flexível à facticidade (HABERMAS, 2002, p. 18). Para tanto, a margem de tolerância do sistema, dentro da qual os valores-meta podem variar sem pôr em perigo crítico sua existência contínua ou sem perder sua identidade, deve ser mantida por meio do respeito às estruturas normativas do sistema, quais sejam, as que permitem a sua identidade. Assim, mantêm-se a coesão e a adequação de seus subsistemas ao conjunto sistêmico.

A complexidade das sociedades atuais engloba, básica e analiticamente, os seguintes subsistemas: o subsistema sociocultural, o subsistema político e o subsistema econômico. O subsistema sociocultural possui, como estruturas normativas, sistemas de status e formas

7 Os valores-meta dos sistemas sociais são produtos, de um lado, dos valores culturais da tradição constitutiva e, do outro lado, dos requisitos não normativos da integração sistêmica. Cf. HABERMAS, 2002, p. 18-19. 
subculturais de vida e apresenta distribuição de recompensas disponíveis privadamente e direitos de dispor. O subsistema político, por sua vez, apresenta as estruturas normativas, que são as instituições políticas do Estado e as categorias de substrato, que são a distribuição do poder legítimo, respectiva força estrutural e racionalidade organizacional disponível. Por fim, o subsistema econômico tem as instituições econômicas (problemas de produção), como estruturas normativas, a distribuição de poder econômico, força estrutural e forças disponíveis de produção (HABERMAS, 2002, p. 18).

Niklas Luhmann, por sua vez, desenvolve uma teoria categorizada no terceiro movimento do pensamento sistêmico, conhecida como dinâmica dos sistemas. É-lhe atribuída, então, a introdução da teoria dos sistemas nas ciências sociais. Na sua intenção de esclarecer o funcionamento da sociedade moderna, Luhmann oferece a configuração de um modo científico apto à explanação das atuais sociedades complexas.

O mote investigatório desse autor é a sociedade complexa. Intitulando seu aporte teórico como Teoria dos Sistemas, Luhmann define a sociedade como sistema social, enquanto conjunto de elementos comunicativos, e vislumbra, como especialização desses elementos comunicativos sociais, a formação de um subsistema que origina o direito, como um conjunto de elementos comunicativos identificados pelo código jurídico. Por tal panorama, vê-se que a delimitação dos fatores concebidos por Luhmann é ditada pela comunicação: são os elementos linguísticos e suas identidades e distinções que promovem a formação dos sistemas e sua especialização. Nesse ponto, como bem trabalhado em minha tese, o autor não considera o sujeito em sua estruturação teórica, mas tão somente as comunicações produzidas por ele. Assim, vislumbra-lhe um aporte descritivo sistêmico, e não deontológico.

O caráter deontológico conferido ao aporte descritivo sistêmico luhmanniano é prescrito por Baggenstoss (2015). Para tanto, fez-se necessária a inclusão, em uma meta-estrutura de pesquisa, do sujeito enquanto produtor dos conteúdos comunicativos e formais e, também, enquanto agente dentro dos sistemas sociais, especialmente o jurídico. Nessa panorama, verifica-se a necessidade de que determinadas funções do sistema jurídico, tipificadas pelas atividades jurisdicional e 
legislativa, fossem exercidas pelos sujeitos de modo que o sistema fosse mantido em evolução, ou seja, em manutenção de suas características básicas, a abertura cognitiva (permitindo a entreda de novos elementos, no caso, comunicativos), e o fechamento operacional (impedindo que outros subsistemas operem dentro de sua estrutura funcional autônoma).

Percebe-se, então, como é possível analisar um determinado fenômeno com objeto de pesquisa. Pelo prisma sistêmico, o fenômeno não é destacado de seu contexto; ao contrário: a observação inexorável é pela estrutura sistêmica em que o fenômeno ocorre, especialmente em relação aos sujeitos envolvidos, às regras comunicativas e aos sistemas vinculados (micro ou macro). Por isso, a constelação surge, de início, como uma forma de se observar um determinado sistema, composto por sujeitos que agem e reagem no ambiente em razão de acordos, expressos ou tácitos, que permeiam a estrutura observada. Posteriomente, então, advém como uma proposta de restauração dos laços havidos entre as pessoas participantes do sistema.

\section{AS CONSTELAÇÕES SISTÊMICAS COMO FORMA DE SE PERCEBER UM SISTEMA}

No contexto brasileiro, as constelações sistêmicas surgem, na última década, como uma proposta de solução para conflitos envolvendo sistemas em que os seres humanos estão envolvidos - e, por tal motivo, passou a ser utilizado em práticas judiciais com relativo cuidado. Em tal panorama, a constelações sistêmicas podem ser definidas como um conjunto de ferramentas que "possibilita a identificação da origem ou do motivo dos conflitos humanos que se escondem por detrás das demandas judiciais", assim, trabalha "padrões destrutivos do comportamento e da interação do sujeito com o grupo familiar ou com seu grupo de convívio, auxiliando na compreensão mútua, potencializando, assim, o restabelecimento do diálogo e prevenindo futuros litígios” (BAGGENSTOSS; FIEGENBAUM, 2017, p. 114). Tal perspectiva é justificada pelo fato de poder relevar dinâmica entre os sujeitos "que ligam o cliente de uma forma disfuncional ao seu sistema de referência, que o limitam em suas potencialidades de ação 
e desenvolvimento pessoal, impedindo-o de estruturar a sua vida de uma forma positiva" (FRANKE, 2012, p. 21) ${ }^{8}$.

Logo, a Constelação pode ser definida como uma técnica que viabiliza, a partir do conhecimento sobre o sistema de pessoas, consequencialmente: (a) a acesso a informações de um determinado campo energéticocomunicacional vinculados às dinâmicas relacionais; (b) esclarecimento sobre determinadas falhas comunicacionais e ocorrências emocionais que impeçam o fluir dos relacionamentos humanos; (c) a conscientização sobre a co-responsabilidade das pessoas participantes das dinâmicas relacionais; (d) a interrupção, pela escolha do sujeito, das ações ou omissões que estejam limitando o bom fluir da sua existência ou de seus relacionamentos e causando um movimento disfuncional à vida e às relações em questão; (e) a assunção de uma nova postura, com a mudança do padrão comportamental.

Tem-se a Constelação Sistêmica como gênero, enquanto técnica de exame de um determinado sistema social; já a Constelação Organizacional (sistema empresarial) e a Constelação Familiar (sistema familiar) são formas específicas de se analisar a técnica.Assim, aplicação da técnica pode se dar em qualquer campo referente a relacionamento humano (empresarial, familiar, escolar, etc..) e pode ou não ter incidência no Direito. Ao Direito, serão relevantes as condutas que estejam juridicamente prescritas. Além disso, é possível, fazer-se a aplicação das Constelações na gestão judiciária, mas não enquanto fato jurídico, mas enquanto perspectiva organizacional.

As ferramentas utilizadas na proposta de Constelação Sistêmica, cuja prática não apresenta regulamentação profissional ou, atualmente, relevantes pesquisas transversais nem longitudinais, formam um conjunto de técnicas conjugadas por diversos conhecimentos, sejam das ciências sociais, biológicas, físicas, ou de cognições extracientíficas, como espirituais e/ou religiosas.

Assim, a abordagem do facilitador pode utilizar conhecimentos:

a) Do campo psicoterapêutico: em que se compreende como as pessoas agem e o porquê agem. As ordens do amor têm incidência aqui, as quais referem-se à lei do pertencimento (no que tange à identificação da pessoa e participação no sistema), à lei da hierarquia (ou precedência, em relação ao respeito à ordem de chegada no sistema) e a lei do equilíbrio (referindo-se à dedicação que as pessoas devem trocar entre si). Tais leis, contudo, não são as únicas a darem um balizamento para a verificação de comportamento. O importante é ter-se, também, uma postura humanista (Carl Rogers), em que se observam os movimentos do sistema, mas não se avaliam positiva ou negativamente - tão somente na orientação para o restabelecimento do posicionamento da pessoa no sistema

\footnotetext{
${ }^{8}$ As Constelações operacionalizam-s “[...] da seguinte forma: em uma reunião com um grupo de pessoas, a pessoa que procurou um serviço de mediação discorre sobre o seu problema ao facilitador e o que almeja como solução. A partir disso, o profissional coleta informações sobre pessoas importantes do núcleo familiar e acontecimentos da vida do mediado, com base no que formula perguntas e hipóteses sobre as dinâmicas familiares presentes no litígio, verificando- as posteriormente na constelação. Para tanto, solicita ao mediado que eleja, entre os participantes do grupo, representantes para si mesmo e para membros da família relacionados à questão narrada pessoas desconhecidas, que podem ser outros mediados envolvidos em lides semelhantes ou não -, posicionandoos no espaço, da forma que melhor lhe aprouver. O facilitador, então, indaga os representantes acerca de suas percepções corporais, sentimentos e sensações, valendo-se dessas informações para pautar o desenvolvimento da dinâmica e perceber onde está o problema e de que forma influencia negativamente o sistema familiar das pessoas em conflito. A partir do que se apresenta, solicita aos representantes que digam frases que o aproximem de uma boa solução, sempre de acordo com o feedback que vêm do próprio mediado, de forma que o que se apresenta faça sentido para ele. Visualizando essa cena, o indivíduo percebe o que efetivamente atuava por detrás de determinados comportamentos conflituosos naquele núcleo, integrando à consciência informações até então inacessíveis que permitem uma nova forma de atuação de sua parte, com outra postura perante o seu próprio sistema familiar”. Cf. (BAGGENSTOSS; FIEGENBAUM, 2017, p. 114-115).
} 


\section{CONEXõES ENTRE PENSAMENTO SISTÊMICO, CONSTELAÇõES SISTÊMICAS E DIREITO SISTÊMICO}

familiar. Esse questionamento das ações não é feito na prática, mas baseiam as referências de onde o sujeito está em seu campo e qual poderia ser o movimento adequado para a resolução de sua questão. Em tal ponto, é o sistema que informará sobre o caminho mais adequado a ser seguido, a partir de suas próprias regras comunicacionais e teleológicas, considerando que todo sistema tem sua linguagem própria.

b) Do campo físico quântico: em que são utilizadas referências relativas de tempo e de espaço, tendo em vista que se considera que o que for observado no sistema não está necessariamente transcrito em uma ordem cronológica;

c) Do campo biológico-médico: a somatização das emoções e de disfunções biológicas são explicadas como não só resultado e/ou potencializações de afetos individuais mal resolvidos, mas também como possível questões não tratadas do próprio sistema.

d) Do campo físico-energético: a energia do ser humano, a partir de Barbara Brennan, e os campos mórficos, de Rupert Sheldrake. É importante destacar que comunicação/informação é energia e geram “entidades” (concentração de energia) e atuam no movimento ou na estagnação do ser humano.

Contudo, o destaque de uma ou outra forma de abordagem, científica ou não, depende da formação e da subjetividade de quem liderará a prática de Constelação, que será denominado facilitador ou constelador. Assim, tem-se inviável a tentativa de rastreamento dos modelos de Constelação aplicados no Brasil, remanescendo, aí, a necessidade de pesquisas regionais e locais para a verificação da linguagem e do conhecimento utilizado.

O modelo de Constelação Familiar, utilizado no Poder Judiciário Brasileiro em mediações familiares, assemelha-se fortemente com a terapia familiar de Abordagem Bioecológica, prática restrita de atuação profissional de psicólogo. Em tal abordagem, o desenvolvimento humano é observado por meio da interação de quatro núcleos inter-relacionados principais, quais sejam: o processo (e suas regras), a pessoa, o contexto e o tempo (BRONFENBRENNER; MORRIS, 1998). Assim, é destacada a interação da pessoa com o ambiente e as outras pessoas em processo recíproco e mútuo.

O ambiente ecológico é o foco de tal abordagem e observa o sistema familiar como "uma série de estruturas encaixadas, uma dentro de outra, que permite avaliar os eventos que influenciam no desenvolvimento humano com maior ou menor potência”. Tais estruturas são os formatos sistêmicos familiares microssistema, mesossistema, exossistema e macrossistema:

O microssistema refere-se às conexões entre pessoas de maneira direta. Consiste em inter- relações face-a-face, no ambiente imediato da pessoa em desenvolvimento e tem características físicas e materiais específicas. O mesossistema é formado por todos os microssistemas nos quais a pessoa em desenvolvimento participa. Esse nível é formado e alterado sempre que esta entra ou sai de um contexto. $\mathrm{O}$ exossistema diz respeito a contextos que talvez a pessoa em desenvolvimento nunca tenha tido contato direto, mas que influenciam o que acontece no seu ambiente imediato. Por fim, o macrossistema diz respeito aos padrões globais de ideologia, história e organização das instituições sociais comuns a uma determinada parte da sociedade ou a esta em sua totalidade. Envolve as consistências que existem ou poderiam existir, permeando os níveis anteriormente descritos, vinculados a qualquer sistema de crenças (PRATI, 2009). 
Faz-se o referido destaque às práticas restritas da psicologia considerando que todo sistema possui fronteiras, que são como limites. No caso dos sistemas envolvendo sujeitos, tem-se os limites de atuação (ex. família, escola, etc), considerando as regras aceitas por aquele conjunto sistêmico. Tal não é diferente com relação às profissões.

As profissões podem possuir regramentos jurídicos, mas também normais convivenciais que são aceitas pelo conjunto de pessoas que representam aquela profissão. Desse modo, é adequado o respeito que os profissionais devem ter dentro de seu sistema e, também, a observância às normas referentes às outras profissões. Nessa perspectiva, é arriscado um profissional da área jurídica se arriscar no manejo de questões que extrapolem os seus conhecimentos humanos e profissionais; da mesma forma, é inadequado que um profissional da área da psicologia pretenda denominar-se afeto à área jurídica e pretenda conduzir questões jurídicas ou pedagógicas.

Nesse sentido, tem em vista que o Poder Judiciário é uma rede institucional de exerce poder sobre um determinado grupo social, a posição de um magistrado como facilitador em constelações familiares pode implicar em uma imposição de conduta, sob o ponto de vista daquele grupo social, e não de, como o nome condiz, facilitador para que sejam dissolvidas as questões disfuncionais e promovidas as funções adequadas para a concretização de seu telos.

A partir disso, imprescindível traçar alguns alinhamentos institucionais acerca das Constelações no contexto do Poder Judiciário Brasileiro a partir das práticas iniciadas pelo magistrado Sami Storch, lotado no interior do Estado da Bahia, em que denominou a prática da Constelação aplicada às questões jurídicas como Dirieto Sistêmico.

\section{A PRÁTICA DA CONSTELAÇÃO FAMILIAR NO PODER JUDICIÁRIO: O CHAMADO "DIREITO SISTÊMICO”}

Sami Storch é o magistrado, lotado na Comarca de Itabuna/BA, que ficou reconhecido nacionalmente no meio jurídico por ter alcançado "[...] índice de acordo de 100\% em processos judiciais onde as partes participaram do método terapêutico" (STORCH, 2018) chamado contelação familiar. Da compreensão de "Constelações”, Storch estabelece que [...]

[...] há dinâmicas ocultas de relacionamento entre as pessoas regidas por leis sistêmicas, que Bert Hellinger (criador das constelações familiares) denominou de "ordens do amor". São três leis básicas: direito ao pertencimento, ordem de precedência e equilíbrio entre dar e receber. Dessas três derivam inúmeras outras, que podemos observar em qualquer relacionamento - principalmente quando ocorre a crise ou conflito, decorrente da violação de alguma das leis sistêmicas (STORCH, 2018). 
A partir disso, infere que a técnica, por isso, pode ser aplicada "na Justiça para trazer à tona as raízes ocultas do conflito/questão e os caminhos para a pacificação/solução, evidenciando-os de forma tocante e mobilizadora para as partes envolvidas” (STORCH, 2018).

Por conseguinte, o magistrado estabelece Direito Sistêmico como "uma ciência dos relacionamentos, válida para relações humanas, organizacionais e relações jurídicas em geral, uma vez que toda relação constitui um sistema ou se constitui dentro de um”. Diante disso, na esfera judicial, sob tal perspectiva, é possível que “[...] cada parte no conflito tem motivos para ter se envolvido nele do modo como fez (seja como agressor, vítima, reivindicador ou devedor)". Tais motivos, segundo o magistrado "podem ter raízes profundas, que não dizem respeito necessariamente à outra parte no processo, mas sim ao passado familiar de cada um, inclusive de gerações anteriores” (STORCH, 2018).

\section{Além disso, define a técnica das seguintes formas:}

a) Nova abordagem para o tratamento dos conflitos na Justiça, denominada Direito Sistêmico, que surgiu da análise do direito sob uma ótica baseada nas ordens superiores que regem as relações humanas, segundo a ciência das constelações familiares sistêmicas desenvolvida pelo terapeuta e filósofo alemão Bert Hellinger (STORCH, 2018b).

b) Trata-se de uma abordagem sistêmica e fenomenológica segundo a qual diversos tipos de problemas enfrentados por um indivíduo (como dificuldades de relacionamento, por exemplo), podem derivar de fatos graves ocorridos no passado não só do próprio indivíduo, mas também de gerações anteriores de sua família. Essa abordagem pode gerar implicações importantes na elaboração, interpretação e aplicação das leis, contribuindo para que juízes, mediadores e outros profissionais da Justiça possam se posicionar de modo a trazer maior paz às relações, bem como para que os conflitos sejam solucionados de forma mais rápida e eficaz, no sentido de conciliações verdadeiras e duradouras (STORCH, 2018b).

Diante da coerência epistemológica do pensamento sistêmico, faz-se imprescindível tecer algumas ressalvas acerca de tal compreensão. A primeira, refere-se à nomenclatura da técnica aplicada em conflitos jurídicos.

Direito, etimologicamente, refere-se à observância, obediência de regras. Contemporaneamente, tem-se como, a grosso modo, um conjunto de normas jurídicas, em sua máxima expressão, que são impostas pelo Estado para a regulação da vida em sociedade. São normas que apascentam as expectativas dos sujeitos de um Estado, como diria Luhmann. Assim, também, o direito, como um todo, pode ser contemplado como um sistema jurídico. 
Qualquer qualificação a ser acrescida contemplará uma especialização do Direito. Por exemplo, direito penal; direito civil; direito administrativo.

Em tal senda de classificação jurídica, a concepção do que seria Direito Sistêmico caracterizaria o significado "conjunto de normas que regulamentam o âmbito dos sistemas". A questão é: as normas dos sistemas não são jurídicas, não são determinadas pelo Estado, não são Direito propriamente dito. A partir de tal categorização, portanto, é incorreta tal nomenclatura.

É viável, no entanto, adotar a compreensão apresentada por Sami Storch de que o Direito Sistêmico é a abordagem sistêmica do Direito, enquanto uma "análise do direito sob uma ótica baseada nas ordens superiores que regem as relações humanas, segundo a ciência das constelações familiares sistêmicas desenvolvida pelo terapeuta e filósofo alemão Bert Hellinger”.

Pois bem.

Além disso, Sami Storch traz essa abordagem como equivalente à única perspectiva sistêmica de análise do Direito, o que não o é. A teoria luhmanniana e a habermasiana, por exemplo, dão conta de analisar o Direito sob prisma sistêmico, sem a adoção dos preceitos estabelecidos por Bert Hellinger. Logo, há várias formas de se promover uma abordagem sistêmica do Direito, sem que necessariamente sejam utilizadas as ordens descritas pelo autor alemão.

Sobre esse ponto, é importante destacar o seguinte: Bert Hellinger descreveu as denominadas Ordens do Amor (Lei do Pertencimento, Lei da Precedência/Hierarquia e Lei do Equilíbrio, mas não é o criador das Constelações Sistêmicas (sejam organizacionais ou familiares) ${ }^{9}$.

Como mencionado anteriormente, conjuntamente com os contrapontos apresentados ao pensamento cartesiano em vários ramos da ciência (em virtude da insuficiência de tal método para a solução de problemas complexos), passou-se a ser consolidada a psicologia sistêmica, a parapsicologia (com Carl Jung, por exemplo) e outras propostas que observação das relações humanas que fomentaram o estudo do inconsciente coletivo familiar, com base na análise sem julgamentos axiológicos (como com Carl Rogers), mas na verificação da comunicação existente entre as pessoas e as possibilidades de reconstrução dos laços familiares. Junto a isso, há estudiosos, como Wilhelm Reich (que pesquisou o inconsciente enquanto energia), Barbara Brennan (aluna de Reiche, astrofísica, pesquisadora da NASA, que atuou nos estudos sobre funcionamento da energia humana), Rupert Sheldrake (biólogo, que consolidou a teoria de morfogênese (teoria dos campos mórficos) - já delineada por Alan Turing -, ), além de Freud e Virginia Satir (psicoterapeuta), que, em seus estudos, contribuíram e contribuem para uma perspectiva sistêmica dos relacionamentos humanos.

Assim, Bert Hellinger, a partir de estudos em áreas terapêuticas, de sua experiência com tribos Zulus e do treinamento que recebeu com Ruth McClendon e Leslie Kari - sobre terapia familiar - promoveu a sistematização desses conhecimentos e descreveu as chamadas Ordens do Amor já referidas (Pertencimento, Ordem e Equilíbrio), as quais são costumeiramente utilizadas nas Constelações Sistêmicas - mas também não são as únicas.

Diante disso, é possível afirmar que:

\footnotetext{
${ }^{9}$ Cf. HELLINGER, Bert. Simetria oculta do amor. Editora Cultrix, 2008; HELLINGER, Bert, Um lugar para os excluídos. Editora Cultrix, 2006.
} 
a) A prática realizada pelo magistrado refere-se à prática terapêutica Constelações Sistêmicas e denominá-la como Direito Sistêmico é etimológica e epistemicamente equivocado;

b) As Constelações Sistêmicas não se confundem com o pensamento sistêmico, visto que este é gênero e, aquelas, espécies;

c) Bert Hellinger não é o idealizador da técnica, visto que representa uma formação prático-terapêutica que alia diversos ensinamentos de variados estudiosos, variando com o prisma adotado pelo seu facilitador;

d) Há outras formas de se conceber as constelações sistêmicas que não pelo pensamento helligeriano ou exclusivamente pelas Ordens do Amor.

Frente a tais exposições, infere-se que, de um plano semântico-cognitivo, as constelações familiares assemelham-se nitidamente com a abordagem terapêutica da psicologia bioecológica, o que, em tese, seria atividade profissional restriva à psicologia. Além disso, verifica-se o equívoco do termo Direito Sistêmico à referência do que seria a técnica das constelações aplicadas a conflitos jurídicos, bem como as concepções equivocadas sobre o surgimento das ferramentas e, também, da própria concepção acerca de sistemas.

\section{CONSIDERAÇÕES FINAIS}

A pesquisa em comento, de caráter documental e bibliográfico, objetivou à solução do questionamento acerca da relação entre pensamento sistêmico, constelação sistêmica e direito sistêmico.

Pelo argumentado, verifica-se que o pensamento sistêmico surge como uma nova forma de observação do mundo, em uma perspectiva de integração dos fatores relevantes em um determinado evento. Em tal contexto, surgiram técnicas terapêuticas que ofertam não a reparação de dano eventual sofrido em um evento danoso, mas, especialmente, a restauração de laços humanos. Nesse ponto, o pensamento sistêmico contribui, como olhar científico, para a reparação do sofrido e para a sustentabilidade da decisão que soluciona o conflito.

Em tal medida, as constelações sistêmicas apresentam-se como uma forma de práticas restaurativas, as quais podem ser aplicadas, igualmente, na esfera judicial, em hipóteses jurídicas. Contudo, a ressalva que aqui se faz encontra guarida na possibilidade de que as práticas mencionadas sejam equivalentes às realizadas restritivamente pela profissão de psicólogo - o que demanda uma pesquisa empírica sobre as práticas e/ou uma atuação estatal para regulamentação da técnica/profissão.

Até aqui, vê-se, portanto, a relação entre pensamento sistêmico e constelação sistêmica. O direito sistêmico, por sua vez, caracterizará a aplicação da constelação sistêmica nos casos judicializados - e, portanto, não demanda uma novel terminologia, visto que a mencionada está incorreta, nos termos sustentados no tópico anterior.

Diante disso, tem-se a resposta ao problema, em que o pensamento sistêmico transveste-se de paradigma científico no qual se embasam várias formas restaurativas, tal como a constelação sistêmica. Nessa linha de pensamento, ainda, o denominada direito sistêmico, em sua nomenclatura, é vazio de conteúdo, visto significar o equivalente à constelação sistêmica aplicada a casos judicializados.

\section{REFERÊNCIAS BIOLIOGRÁFICAS}


ALVES, João Bosco da Mota. Teoria geral de sistemas: em busca da interdisciplinaridade. Florianópolis: Instituto Stela, 2012.

ANDRADE, Aurélio L. Curso de pensamento sistêmico: caderno de campo. São Paulo: Digital Publish \& Print, 2014.

BAGGENSTOSS, Grazielly A. Teoria dos sistemas humanizada: a modelagem garantista das funções jurisdicional e legislativa. Rio de Janeiro: Lumen Juris, 2015.

BAGGENSTOSS, Grazielly A.; FIEGENBAUM, Magda. A eficácia das constelações sistêmicas como método de pacificação dos conflitos familiares. Formas consensuais de solução de conflitos [Recurso eletrônico online]. VII ENCONTRO INTERNACIONAL DO CONPEDI/BRAGA - PORTUGAL. Organização CONPEDI/ UMinho, 2017.

BERTALANFFY, L. von. General System Theory: foundations, development, application. New York : George Braziller, 1969.

BRONFENBRENNER, U.; MORRIS, P. The ecology of developmental processes. New York: John Wiley \& Sons, 1998.

CAPRA, Frijot. A teia da vida. 13 ed. São Paulo: Cultrix, 1999.

CAPRA, Frijot. O ponto de mutação: a ciência, a sociedade e a cultura emergente. São Paulo: Cultrix, 2012.

COLOM, Antonio. A (des)construção do conhecimento pedagógico: novas perspectivas para a educação. Porto Alegre: Artmed, 2004.

CONJUR. Doze tribunais adotam técnica alemã de conciliação em conflitos Disponível em <https://www.conjur.com.br/2016-nov-01/doze-tribunais-adotam-tecnicaalema-conciliacao-conflitos>. Acesso em 28 mar 2018.

CONSELHO NACIONAL DE JUSTIÇA. "Constelação Familiar" ajuda a humanizar práticas de conciliação no Judiciário. Disponível em <http://www.cnj.jus.br/noticias/cnj/83766constelacao-familiar-ajuda-humanizar-praticas-de-conciliacao-no-judiciario-2> Acesso em 28 mar 2018; e

FRANKE, U. Quando fecho os olhos vejo você: as constelações familiares no atendimento individual e aconselhamento: um guia para prática. 2. ed. Goiânia: Atman, 2012.

HABERMAS, Jürgen. A inclusão do outro: estudos de teoria política. São Paulo: Edições Loyola, 2002.

HELLINGER, Bert. Simetria oculta do amor. São Paulo: Editora Cultrix, 2008.

HELLINGER, Bert. Um lugar para os excluídos. São Paulo: Editora Cultrix, 2006.

LAKATOS, Eva Maria; MARCONI, Marina de Andrade. Fundamentos de metodologia científica. São Paulo: Atlas, 1991. 


\section{CONEXÕES ENTRE PENSAMENTO SISTÊMICO, CONSTELAÇÕES SISTÊMICAS E DIREITO SISTÊMICO}

PRATI, Laíssa Eschiletti. Práticas dos terapeutas familiares brasileiros: a perspectiva da abordagem bioecológica do desenvolvimento humano (Tese). Instituto de Psicologia, PPGP - UFRGS, 2009.

STORCH, Sami. Direito sistêmico: a resolução de conflitos por meio da abordagem sistêmica fenomenológica das constelações familiares. Disponível em <https://direitosistemico.wordpress.com/2017/09/22/artigo-descreve-modelo-original-depratica-de-constelacoes-na-justica-e-aplicabilidade-do-direito-sistemico/> Acesso em 20 mar 2018b.

. Por que aprender direito sistêmico. Disponível em $<$ https://direitosistemico.wordpress.com/2017/04/10/por-que-aprender-direito-sistemico/> Acesso em 20 mar 2018a.

TRINDADE, André Karam. Para entender Luhmann: e o direito como sistema autopoiético. Porto Alegre: Livraria do Advogado, 2008. 